\title{
An Evaluation of Critical Factors Influencing Product Innovation in the Food Industry — A Case Study of China Mengniu Dairy Company
}

\author{
Bei Ju \\ International Business Faculty, Beijing Normal University Zhuhai Campus \\ Jingfeng Road 18, Tangjia Bay, Zhuhai 519087, People's Republic of China \\ Tel: 86-756-6126-6000 E-mail: j19821111@gmail.com
}

$\begin{array}{ll}\text { Received: October 17, } 2011 & \text { Accepted: November 29, } 2011 \quad \text { Published: February 1, } 2012 \\ \text { doi:10.5539/ijbm.v7n3p104 } & \text { URL: http://dx.doi.org/10.5539/ijbm.v7n3p104 }\end{array}$

\begin{abstract}
This paper aims to identify the critical factors influencing product innovation in the food industry and explore their roles in Chinese food company. It firstly identifies three key factors that impact on product innovation in the food industry focusing on the literature review of innovative factors in the food industry and its characteristics. Then enlightened by a case study of China Mengniu dairy company, the importance of each factor is assessed which shows that in the Chinese food industry market research is most critical for product innovation. Strategy is also the crucial factor and technology plays a comparatively weak role. The findings indicates that the factors influening product innovation can be diverse due to target industry and its characteristics. Therefore futher studies are encouraged to expolre the roles of factors crucial to product innovation in other industries in China.
\end{abstract}

Keywords: Critical factors, Product innovation, Food industry

\section{Introduction}

It is widely recognized that innovation is of great importance to competitiveness and success in many industries by means of creating values and sustaining competitive advantages. As a result, the topic of the critical factors influencing successful innovation has received extensive discussion. In the context of the food industry, it is regarded as strongly market-driven and rapidly changes in response to consumers' preference and tastes. Under this dynamic market condition, the innovation defined by Tidd et al. (2001, p.38) as "a process of turning opportunity into new ideas and putting these into widely used practice" is highly pursued by many food companies to gain their competitive advantages.

In the light of the features of food industry, the factors that contribute to its innovation, especially the product innovation are identified and analysed in this paper. By comparison, the key factors of more importance are emphasized. Furthermore, China Mengniu dairy company is taken as an example to illustrate how the critical factors contribute to successful innovation in an explicit way.

\section{Literature background}

\subsection{Characteristics of food industry}

Generally speaking, the food industry has a long history and gained a rapid development after the industrial revolution. Core food industry activities include food manufacturing, warehousing, distribution and retailing. In this paper, the food manufacturing industry is highlighted under the specific context due to its popularity and significance. In terms of the food industry, it is of distinctive features differing from the service industry which highlights the cooperation, collaboration and efficient communications. It is also widely recognized that (Fryer and Versteeg, 2008) most companies in the food industry are small or medium but they occupy a large fraction of the market although there are some major multinational companies with global brands. Due to this, the structure of the food industry is quite different from the pharmaceutical industries in which the large multinationals tend to play the dominant role in the whole industry. In this sense, the variety of products is placed as one of the features in the food industry, which contributes to the significant role of the product 
innovation. Furthermore, the food industry, characterized by market driven and responsive to consumer needs, is of constant changes all the time. To meet the satisfaction of consumers, Pinggali (2007) states that the food sector is faced with major challenges that arise from changes in the sector's economic and non-economic environments, from changes in lifestyles, from possible climatic changes, from global increases and changes in food consumption, which impact the input supply industries and agriculture to food processing, food distribution, and retail. To be more specifically, Fryer and Versteeg (2008) summarized the key elements in the food industry as food safety, health and well-being, high quality, convenience, price, environment, sustainability. In the recent years, the food industry is given the new opportunities to develop new functional and nutritious products with the growth in consumer's interest in health and wellness, which makes the food industry highly innovative. Therefore, the food industry is chosen as the specific context to explore the critical factors for innovation.

\subsection{Critical factors influencing innovation in the food industry}

A great deal of literature examines the critical factors affecting innovation. More specifically, some researchers also explore the innovative factors in the specific field apart from the general discussion of success factors for innovation.

In terms of the variation of industry and innovation, five innovation factors linked to information technology are identified by Johannessen (1994) as the role of the change agent, organisation culture, management style, the market and co-ordination and service. Merx-Chermin and Nijhof (2005) propose the innovation process model consisting of knowledge creation, innovation and learning to learn and identify the factors that might influence the cycle such as added value for stakeholders, leadership, climate, structure and strategic alignment. Moreover, Pandey and Sharma (2009) explore the role of culture, innovation \& technology management and leadership styles in the initiation and implementation phases of the innovation. The findings of Chamberlin et al. (2010) are that the most important factors are standard business imperatives such as satisfying existing customers, skilled workers culture knowledge, etc when examining the relationship between innovation and business success factors. Of the great number of studies, the agreement exists when examining the positive impact on innovation affected by factors although it has been found that various studies remain inconsistent with respect to factors such as strength of competition, R \& D intensity and top management support (Van der Panne et al., 2003). Among these success factors for innovation, their relationships are regarded as independent, which is developed in the studies of Smith et al. (2008). They not only identify nine key factors that impact on innovation management in organisation, namely organisational culture, management style and leadership, resources, organisational structure, strategy, technology, knowledge management, employees, and innovation process, but also find the common relationships existing among them.

In spite of the diverse selections of sectors or industries, it has come to the agreement on the common factors for successful innovation. Accordingly, this paper partly aims to examine whether these factors are still critical in the food industry and how important they are.

On the other hand, another key concept to identify the factors for innovation is the type of innovation. In response to different types of innovation, successful factors influencing innovation will vary in the specific context. In the early times Knight (1967) proposed the classification of innovation, which is made up of product or service innovation, product-process innovation, organisational structure innovation and people innovation. Based on a range of previous studies on types of innovation (Francis \& Bessant, 2005; Trott, 2005; Oke et al. 2007), Rowley et al. (2011) put forward a new framework of types of innovation including product innovation, process innovation, position innovation and paradigm innovation.

In the light of this new framework and the characteristics of food industry, the critical factors for innovation in the food industry can be mainly classified into such two types as product innovation and process innovation. In terms of product innovation, researchers have suggested that the positive roles of strategy, processes to market and technology in product development (Hoban, 1998; Hollingsworth, 1998). Herath et al. (2008) find the positive role of product development in the market sharing. In addition, Thompson and Moughan (2008) discuss the drive force of functional foods which can improve health and well-being by the consumption behind the growth of the food industry. To compare the importance of the factors in launching the new food product, the quantitative research administrated by Suwannaporn and Speece (2010) suggests that the use of marketing research is most critical. Internal communication and supplier linkages are also predictors of success rate and strategy and planning plays a weak role. Therefore, it is necessary to further identify and prioritise the success factors for innovation in the whole food industry.

From the perspective of process innovation, Fryer and Versteeg (2008) provide an overview of a number of technical processes that have provided advantages to the consumer and the food industry and suggest the linking 
the industry needs and the technical understanding. Furthermore, Roupas (2008) examines the roles of factors like human and organisational traits, thinking patterns, attitudes and behaviours towards innovation in promoting innovation in the food manufacturing industry.

Compared with the process innovation, the food industry is more innovative in terms of product innovation according to Fryer and Versteeg (2008). The primary reason is the low margins under which the industry operates. This leads to the unwillingness to invest in new plant and process unless the benefit and rapid payback can be achieved. Secondly, it is the resistance to new processes on account of the potentially negative response by consumers. Consequently, the product innovation is finally decided as the objective and then the critical factors influencing product innovation are evaluated in the food industry.

\section{Evaluation of the critical factors for innovation in the food industry}

By integrating the literature review of characteristics of food industry and critical factors for innovation in the food industry, three critical factors influencing product innovation in the food industry are identified. Then the importance of each factor is measured and the priority list comes up. Finally, China Mengniu dairy company is adopted as a case to exemplify these factors for innovation in the food industry.

\subsection{Identifying the critical factors influencing product innovation in the food industry}

The key factors affecting innovation in the food industry are identified and shown in the figure 1, which is developed on propositions put forward by Smith et al. (2008) and Rowley et al. (2011) mentioned in the second part along with the review of factors for product innovation in the food industry. To be more specific, it can't be ignored that the existence of common key factors for innovation found by Smith et al. will definitely be feasible in the food industry. Then by the comparison of previous studies on innovation in food industry, the critical factors including strategy, processes to market and technology in product development are found to be important in product innovation which is initially examined by the quantitative research (Suwannaporn and Speece, 2010) in a further way. As a result, the three critical factors for product innovation in the food industry are identified.

\subsection{Assessment of the critical factors for product innovation in the food industry}

The food industry is characterized by market driven and responsive to consumer needs, which calls for the constant improvement in products. In the efforts to become more competitive in this industry, the market research is the decisive and primary step. The common market research techniques adopted by the companies to generate consumer information include surveys, focus groups and in-depth interviews. By means of market research, the consumer's preference and taste are discovered. Based on the result of market research, the companies are accessible to the modification of current products as well as the opportunity of developing new products, which will absolutely contribute to the success of new product development. On the other hand, the application of market research is also able to learn about the competitors and macro-environmental forces in the marketplace. By orientating the consumer and market conditions through market research, the food companies is capable of getting the clear understanding of the consumer' needs and then make their decisions in the context of the current market circumstances, which will result in the successful product innovation. The importance of market research in the product innovation has been identified by the Cooper and Kleinschmidt (1995), who suggest that effective market research results in sharp product definition which is a drive of product success. In addition, Suwannaporn and Speece (2010) report that use of marketing research is most critical in the Thai food industry.

Technology, as one of the critical factors influencing the product innovation in the food industry, can accelerate the manufacturing process and assist with new product development. More specifically, technology used in the product innovation of food industry can be mainly divided into three types. First of all, the technology can play the supportive role in the marketing research to test consumer and market and then analyse the collected data. Secondly, the new technology is used in the product line to increase productivity and in the food package as well. Thirdly, most food companies use the technology to add the new ingredients into their product and then develop more nutritious and healthier food products which can be termed as the 'functional foods'. The drives behind the consumption of functional foods are promotion of health and the prevention of disease. With the assistance of technology, the innovative ideas of products generated from market research finally turn into reality. Just as Fryer and Versteeg (2008) conclude that the industry needs is required to be tied with the technology understanding to create new commercial processes.

The third factor, strategy, provides the vision and goals for company to innovate and the focus of product development. This factor, more exactly to be new product strategy, guidelines the product innovation to immediately adapt to changing conditions and new information under the context of food industry. Additionally, 
the strategic consideration about the role and positioning of new products in the company will definitely contribute to the success of the product innovation. Without it, the product innovation may take the risk of being ambiguous implementation which is reinforced by the findings of Nicholas et al. (2011). They report that strategy is viewed as the most crucial new product development dimension.

Compared with innovations in other industries, such as the tourism industry, the factors for successful innovation are of significant difference. Tourism is not a single product but an experience, which can be defined as services provided by travel agency, hotels, and channels of transportation. The products of tourism industry are all intangible services and are not easy to be standardised due to such unpredictable elements as people and climate. Faché (2000) reports the importance of quality management in tourism innovation. Also the evidence presented by Perdomo-Ortiz et al. (2006) indicates that the positive role of quality management, especially the importance of knowledge management for successful innovation. Additionally, Byrd et al. (2008) conclude that stakeholder involvement is a critical part of sustainable tourism development. Therefore, the innovation in the tourism industry is greatly dependent on these factors including knowledge management, management styles and people, which will enhance the internal and external communications and collaborations. In this way, the quality of services will be ensured.

In fact, the three factors for successful product innovation including market search, technology and strategy are independent of each other. With the assistance of technology, market research is the initial step to carry out the product innovation and it plays the crucial role in deciding the variety of new products. Therefore, market research is the most important factor for product innovation. The strategy factor guilds the whole new product development process by offering the clear positioning and role of new product. Its role is examined in the latest quantitative research done by Nicholas et al. (2011), which reports that the strategy is of high importance, and other dimensions such as process, project climate and company culture are of medium or low importance. To some extent, it is comparatively more important than technology which only plays the role as supporter. In a general way, the importance of three factors for product innovation in the context of food industry can be described in the priority list as: market research, strategy and technology.

\subsection{A case study of China Mengniu dairy company}

In this paper, China Mengniu dairy company is taken as an example to evaluate the three critical factors for product innovation in the food industry. Founded in 1999 and based in Inner Mongolia, Mengniu dairy company has grown rapidly to become the leading milk producer in China. So far the its principal products are liquid milk (UHT milk, milk beverages and yogurt), ice cream, and other dairy products such as milk powder, milk tea powder, tablets and cheese. There is no doubt that innovation is the secret that lies behind its significant success and this is also the reason why Mengniu company is chosen as the representative of food companies in China.

According to the statistics, Mengniu has 330 brand registrations in and out of China and 615 national patents including 63 invention patents and 540 product design patents. Its variety of products indicates that the product innovation is of the great importance. At the beginning of 2006, the yogurt drink "Suan Suan Ru" featuring as more nutritious and capable of being absorbed by the human body was launched into the market with response to the market trends of healthy food. As a result of its market research which shows the preference of the young consumers, Mengniu dairy company has modified the packaging of its sweet and sour fruit milk drinks to attract young adults. Moreover, inspired by its market research analysis to meet the taste and nutrition needs of consumers, its new product, UHT (Ultra-High-Temperature) milk drink containing real pieces of fruit such as strawberry, peach, coconut and aloe and it has gained a sales hit in China. With response to the consumers' age, gender, salary and preference, the company conducts the market research each year and makes the corresponding changes in their products to meet the market and consumer's need, which is conducive to the company's rapid expansion and dominant role in China's dairy industry.

However, the milk products lose their high quality when the dairy company sparing their great efforts on developing innovative products. In 2008, Mengniu dairy company was among 22 dairy companies found to have sold products containing the toxic chemical used to make plastics and thus underwent dramatic profit drop which gave a dramatic shock to its image and profit.

The strategic approach of Mengniu dairy company on its initial stage development can be defined as diversification. Its products also include ice-cream, milk-powder and beverage with no restrained to milk products. Secondly, it focuses on high-end functional products for the women, children and urbanites in recent years. With this guideline, the company continues its product innovation and positions them as functional, healthy and green products. For instance, Mengniu has launched the Guanyi lactic acid milk. To present the concept of health in the eyes of Chinese consumers, the company develops a new yogurt with red jujube taste. In 
addition, its health care milk and gold package power milk Zhijiayi have completely represented its new product strategy which emphasizes the idea of green and healthy food. Thirdly, it devotes to the industrial development in an ecological friendly way and puts great efforts to strive for low-carbon economy. The new visions have the great impact on its product innovation and thus advances with times.

The technology accelerates the manufacturing process and assist with new product development. In Mengniu, a new filling technology allows UHT milk drinks with fruit pieces to be rapidly filled in $250 \mathrm{ml}$ cartons, which makes its milk drink popular and successfully. Without this technology, the new products are unable to be launched into the market. Moreover, an innovative way is developed to make sterols dissolve easily in water while maintaining the milk's superior taste and appearance. On April $18^{\text {th }} 2011$, the post-doctoral center of Mengniu was established to ensure the wide application of new technology in the product development. Additionally, its New Channel milk, the first nutritious dairy products for female in China indicates the innovation of technology. In other words, the supportive role of technology makes the product innovation easier and efficient.

\section{Conclusions and implications}

This paper has identified the critical factors influencing product innovation in the food industry and explore their roles in Chinese food company. Focusing on the literature review of innovative factors in the food industry and analysis of its characteristics, the findings indicates that the factors influencing product innovation can be diverse due to target industry and its characteristic. In the food industry, three crucial factors for product innovation are identified as market research, technology and strategy and they are independent to each other. Such two factors as technology and strategy included in the nine key factors for successful innovation are also proved to be crucial in the food industry.

Enlightened by a case study of China Mengniu dairy company, the role of each factor is assessed and their importance is summarized in the priority list. Market research is placed as the most important factor for product innovation in the food industry which is driven by market and consumers' preference. The role of strategy is also important acting as the guideline to endure the development of product innovation. Finally technology plays a comparatively weak role of supporting by turning the innovative ideas into realization. By the case study of China Mengniu dairy company, it is also suggested that although the new product development is of great significance, the food quality should not be sacrificed at any cost.

The results of this paper are mainly drawn by means of literature review and case study, which calls for further quantitative research in the further studies which are encouraged to explore the roles of success factors in other industries aside from the food industry in China.

\section{References}

Byrd, E.T., Cardenas, D.A., and Greenwood, J.B. (2008). Factors of stakeholder understanding of tourism: The case of Eastern North Carolina. Tourism and Hospitality Research, Vol.8 No, 3 pp. 192-04. http://dx.doi.org/10.1057/thr.2008.21

Chamberlin, T., Doutriaux, J., and Hector, J. (2010). Business success factors and innovation in Canadian service sectors: an initial investigation of inter-sectoral differences. The Service Industries Journal, Vol.30 No, 2 pp. 225-46. http://dx.doi.org/10.1080/02642060802120174

Cooper, R.G., and Kleinschmidt, E.J. (1995). Benchmarking the firm's critical success factors in new product development. Journal of Product Innovation Management, Vol.12 No 5, pp. 374-91.

Faché, W. (2000). Methodologies for innovation and improvement of services in tourism. Managing Service Quality, Vol.10 No.6, pp. 356-66. http://dx.doi.org/10.1108/09604520010351185

Francis, D., and Bessant, J. (2005). Targeting innovation and implications for capability development. Technovation, Vol.25 No.3, pp. 171-83. http://dx.doi.org/10.1016/S0166-4972(04)00052-5

Fryer, P.J., and Versteeg, C. (2008). Process technology innovation in the food industry. Innovation: Management, Policy and Practice, Vol.10 No.1, pp. 74-90. http://dx.doi.org/10.5172/impp.453.10.1.74

Herath, D., Cranfield, J., Henson, S., and Sparling, D. (2008). Firm, market and regulatory factors influencing innovation and commercialization in Canada's functional food and nutraceutical sector. Agribusiness, Vol.24 No.2, pp. 207-30.

Hoban, T.J. (1998). Improving the success of new product development. Food Technology, Vol.52 No.1, pp. 46-49. 
Hollingsworth, P. (1998). New rules for success in food research. Food Technology, Vol.52 No.5, pp. 76-79.

Johannessen, J. (1994). Information technology and innovation: identifying critical innovation factors. Information Management and Computer Security, Vol.2 No.2, pp. 4-9. http://dx.doi.org/10.1108/09685229410059532

Kinght, K.E. (1967). A descriptive model of intra-firm innovation process. Journal of Management, Vol.40 No.4, pp. 478-96. http://dx.doi.org/10.1086/295013

Merx-Chermin, M., and Nijhof, W.J. (2005). Factors influencing knowledge creation and innovation in an organization. Journal of European Industrial, Vol.29 No.2, pp. 135-47.

Nicholas, J., Ledwith, A., and Perks. H. (2011). New product development best practice in SME and large organizations: theory vs practice. European Journal of Innovation Management, Vol.14 No.2, pp. 227-51.

Oke, A., Burke, G., and Myers, A. (2007). Innovation types and performance in growing UK SMEs. International Journal of Operations \& Production Management, Vol.27 No.7, pp. 735-53. http://dx.doi.org/10.1108/01443570710756974

Pandey, S., and Sharma, R. (2009). Organizational factors for exploration and exploitation. Journal of Technology Management and Innovation, Vol.4 No.1, pp. 48-58. http://dx.doi.org/10.4067/S0718-27242009000100005

Perdomo-Ortiz, J., Gonzalez-Benito, J., and Galende, J. (2006). Total quality management as forerunner of business innovation capability. Technovation, Vol. 26 No.10, pp. 1170-85. http://dx.doi.org/10.1016/j.technovation.2005.09.008

Pingali, P. (2007). Westernization of Asian diets and the transformation of food systems: implications for research and policy. Food Policy, Vol. 32, pp. 281-98. http://dx.doi.org/10.1016/j.foodpol.2006.08.001

Roupas, P. (2008). Human and organizational factors affecting technology uptake by industry. Innovation: Management, Policy and Practice, Vol.10 No.1, pp. 4-28. http://dx.doi.org/10.5172/impp.453.10.1.4

Rowley, J., Baregheh, A., and Sambrook, S. (2011). Towards an innovation-type mapping tool. Management Decision, Vol.49 No.1, pp. 73-86. http://dx.doi.org/10.1108/00251741111094446

Smith, M., Busi, M., Ball, P., and Van der Meer. R. (2008). Factors influencing an organization's ability to manage innovation: A structured literature review and conceptual model. International Journal of Innovation Management, Vol.7 No.4, pp. 655-76.

Suwannaporn, P., and Speece, M.W. (2010). Assessing new product development success factors in the Thai food industry. British Food Journal, Vol. 112 No.4, pp. 364-86. http://dx.doi.org/10.1108/00070701011034394

Thompson, A.K and Moughan, P.J. (2008). Innovation in the foods industry: functional foods. Innovation: Management, Policy and Practice, Vol.10 No.1, pp. 61-73. http://dx.doi.org/10.5172/impp.453.10.1.61

Tidd, J., Bessant, J., and Pavitt, K. (2001). Managing Innovation: Integrating Technological, Market and Organisational Change ( ${ }^{\text {nd }}$ Edn.), Chichester: John Wiley \& Sons Ltd.

Trott, P. (2005). Innovation Management and New Product Development. Prentice-Hall, Harlow.

Van der Panne, G., van Beers, C., and Kleinknecht, A. (2003). Success and failure of innovation: a literature review. International Journal of Innovation Management, Vol. 7 No.3, pp. 309-38. 


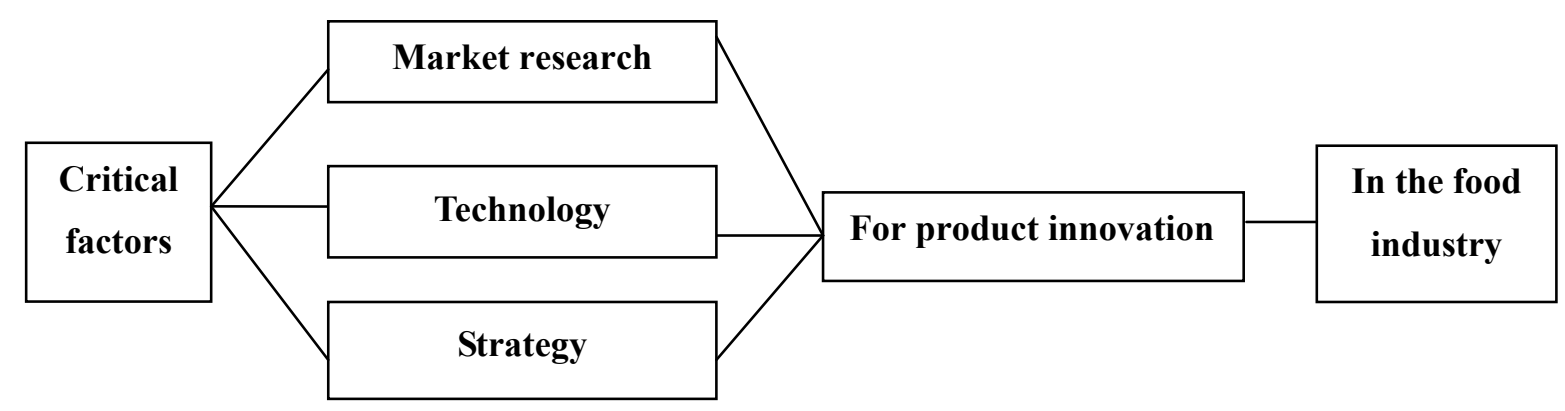

Figure 1. Critical factors for product innovation in the food industry

As it is shown in the figure 1, the innovation in the food industry focuses on the product innovation which refers to the current product modification and new product launched into the market as well. There are two reasons why the product innovation is emphasized in the food industry. Firstly, the food industry is characterized as variety of products and rapidly changing consumer needs, thus product innovation plays the crucial role. Secondly, the food industry seems highly innovative in terms of product innovation, but the process innovation is much less. Such factors as technology and strategy are not only the common critical factors influencing innovation but also the important factors for innovation examined in the food industry. Another factor, market research has been examined by the quantitative analysis to be of the greatest importance in new product development (Suwannaporn and Speece, 2010). Therefore, these three critical factors including technology, strategy and market research are identified as the critical factors for product innovation in the food industry. To be clearer in this paper, the meaning of each factor as well as their importance is described as following:

Market research is relevant to the use of marketing research techniques to capture consumer purchase patterns and market environment for further analysis and decision-making.

Technology means the adoption of advanced technology in the food processing to produce or pack the food.

Strategy refers to the vision of the organisation and its strategic decision. 